\title{
Effect of Pre-Heated Air on Spark Ignition Engine Fuelled with Petrol-Ethanol Blends
}

\author{
R. Sameeth Raj, S. Lesslins Raja Deva Doss N. Surendar, S. Gowthaman
}

\begin{abstract}
Bio-fuels have been made vital developments from past decades, in which bio-petrol plays a major role in SI engines. Developments in petrol-ethanol blends have been made to improve the efficiency of SI engine. Air preheated is supported widely in preheating of intake air. To improve efficiency and to reduce emission, air preheated is used in many systems. SI engines are used in automobiles, motor cycles, aircrafts, motorboats and portable small engine. In this work, investigations have been done in the SI engine which intakes preheated air-fuel mixture and various blends of ethanol petrol fuel is used as working fuel. Emission tests are done by exhaust gas analyzer to compare the emissions of different fuels.
\end{abstract}

Keywords: Preheated air, SI Engine, Homogenous mixture, Reduced Pollutants.

\section{INTRODUCTION}

Air pollution has major role in increasing global concern, which pushes scientists and people to take much importance in the environmental friendly alternative fuels. Because of increasing fossil fuel demand and their exhaust emission, this is to becoming choice of alternative fuels for internal combustion engines. From the day when automobile are invented alcohols are been recommended as fuels for internal combustion engines. In any case, some inadequacies of alcohols, for example, unpredictability in their introduction and a few unacceptable properties for engines have confined their basic usage.

Many of the one-of-a-kind alcohols ethanol is the terrific healthiest fuel for sparkle begin (SI) engines. The most super residences of ethanol as a SI engine fuel are that it has excessive octane wide variety, fire speed and improved thermal effectiveness due to increased compression ratio strain. Ethanol may be applied in as unadulterated or through blending with gas in SI automobiles. Unadulterated situation of ethanol calls for couple of modifications on engine plan

Revised Manuscript Received on December 05, 2019.

* Correspondence Author

R. Sameeth Raj, UG Student, Department of Automobile Engineering Kalasalingam Academic of Research and Education, Krishnankoil, Srivilliputtur, Tamilnadu, India-626126, Email: deepakpraveen420@gmail.com

S. Lesslins Raja Deva Doss, UG Student, Department of Automobile Engineering Kalasalingam Academic of Research and Education, Krishnankoil, Srivilliputtur, Tamilnadu, India-626126, Email:

N. Surendar, UG Student, Department of Automobile Engineering Kalasalingam Academic of Research and Education, Krishnankoil, Srivilliputtur, Tamilnadu, India-626126, Email:

S. Gowthaman, Associate professor, Department of Automobile Engineering Kalasalingam Academic of Research and Education, Krishnankoil, Srivilliputtur, Tamilnadu, India-626126, Email: gowthammech@hotmail.com and gas framework whilst it thoroughly may be applied at low focuses in SI vehicles with the aid of blending with fuel and not using a adjustments of the SI vehicles. It turned into accounted for that using ethanol-gas mixes such as ethanol at low fixations may want to improve motor execution and fumes emanations.

Its miles imperative to inspect that the optionally available fuel utilized as alternative must be constructed from the inexhaustible resources and available sources need to be contrived to utilize this fuel without leading any adjustments within the geometry of the motor. Liquor has given a response to this difficulty. Hence, the ethanol is very a great deal idea out to be the maximum becoming gasoline for sparkle start (SI) engines. The stores of the oil based totally gasoline are straightforwardly related to the increasing request of human beings for vitality era. With the development in general populace, enterprises, cars, and hardware, vitality request result in the hunt for the bogus of oil fuel that may oblige the want of people today. This audit paper focuses to investigate the advances in improving the exhibition of the run motor with fluctuating stage of mixes of gasoline ethanol and reflect on consideration on emanations.

SI engine - spark ignition engine is an internal combustion engine, generally a petrol engine, where the combustion process of air fuel mixture is ignited by a spark from a spark plug. This is in difference to compression- ignition engines, typically diesel engines, where the heat is generated from compression together with the injection of the fuel is enough to initiate the combustion process, without needing any external spark.

Spark-ignition engines are commonly referred to as "gasoline engines" in North America, and "petrol engines" can run on fuels other than petrol/gasoline, such as methanol, auto gas (LPG), compressed natural gas (CNG), ethanol, hydrogen and nitro methane (in drag racing), bioethanol.

\section{ALCOHOL AS A FUEL FOR IC ENGINE}

Alcohol fuels are also known as

non-conventional fuels. The important feature of alcohol is, it can be obtained from both natural and manufactured sources. Mostly natural gases are used to produce alcohol. By some chemical process alcohols can also be produced from biomass.

Two kinds of the alcohol fuels are,

1. Methanol

2. Ethanol 
Alcohols are made from corn, wheat, sugarcane, tree, etc. Also alcohol fuels are cost less when compared to petroleum fuels. The friendly fuel available till now is alcohol fuels. Alcohol has high octane number and less flash point temperature than petrol. This helps to increase the efficiency of the engine that results in fuel economy.

Alcohol blended fuel are used worldwide. Considering E10 which contains ethanol $10 \%$ and petrol $90 \%$ helps engine to increase its efficiency by $15 \%$. Also alcohol fuels are less emission than petrol. On an average alcohol fuels reduce emissions by $30 \%$.

\section{EXPERIMENTAL SETUP}

The experimental investigations have been carried out on single cylinder, four stroke petrol engine. The engine was slightly modified and adopted the heater. The experimental investigation of two wheeler engine is shown in figure 5.1 and figure 5.2.

During the experimental investigation the engine was operated with different speeds such as $200 \mathrm{rpm}, 400 \mathrm{rpm}, 600$ $\mathrm{rpm}, 800 \mathrm{rpm}$ and $1000 \mathrm{rpm}$ and absorbed the performance and emission characteristics.

Table 1: Experimental setup specifications

\begin{tabular}{|c|c|}
\hline Engine type & 4 stroke \\
\hline Ignition type & Spark ignition \\
\hline No of strokes & 4 \\
\hline Engine displacement & $124.73 \mathrm{cc}$ \\
\hline Power (PS@rpm) & 10.30 PS@7500 rpm \\
\hline Torque (Nm@rpm) & $10.30 \mathrm{Nm} @ 5500 \mathrm{rpm}$ \\
\hline Bore & $52.4 \mathrm{~mm}$ \\
\hline Stroke & $57.8 \mathrm{~mm}$ \\
\hline
\end{tabular}

\section{RESULTS AND DISCUSSION}

\section{A. Performance Characteristics}

\section{Specific Fuel Consumption}

Specific fuel consumption is the determination of the fuel efficiency of any engine that combusts fuel and produces rotational power. Generally, it is used to compare the efficiency of internal combustion engines with a shaft output. It is the ratio of fuel consumption to the power produced.

Specific fuel consumption should be less which will result in higher efficiency. In order to achieve higher efficiency specific fuel consumption is less at $1000 \mathrm{rpm}$ with petrol while comparing with other fuels used.



Fig 2: Engine speed vs Specific Fuel Consumption

\section{Brake Thermal Efficiency}

Brake Thermal Efficiency is determined as break power of a heat engine as a result of the thermal input from the fuel. It is used to determine how effectively a fuel is converted into mechanical energy.

From the above graph the Brake Thermal Efficiency is higher wit petrol as fuel and at engine speed of $1000 \mathrm{rpm}$ which is nearly $26 \%$. The achieved Brake Thermal Efficiency is higher when compared to the Brake Thermal Efficiency at $200 \mathrm{rpm}$ with the same fuel petrol.

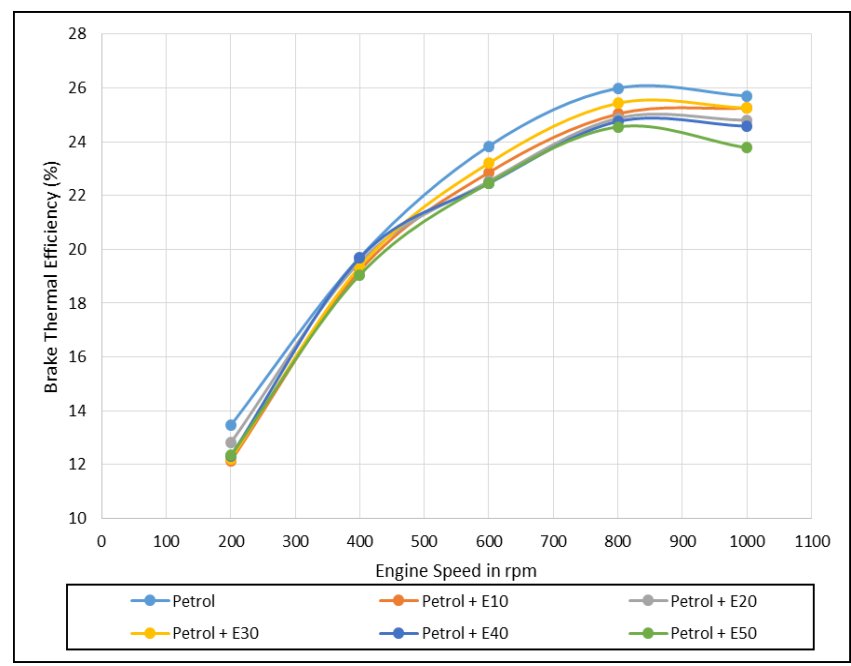

Fig 5: Engine speed vs Brake thermal efficiency

\section{B. EMISSION CHARACTERISTICS}

\section{Particulate Matters}

Environmental airborne particles - otherwise called barometrical particulate issue, particulate issue, particulates, or suspended particulate issue - are tiny strong or fluid issue suspended in the air of Earth.

Particulate matter should be less in order to achieve less emission. As observed from the above graph the particulate matters are less at $200 \mathrm{rpm}$ with fuel as E30 (Ethanol 30\% blended with $70 \%$ petrol). 


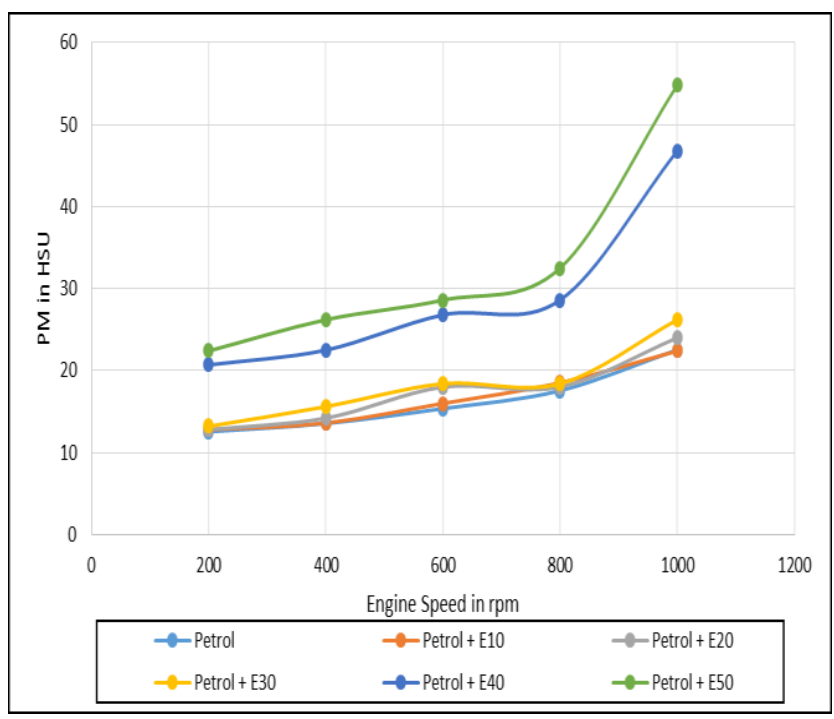

Fig 6: Engine speed in rpm vs particulate matters in HSU

\section{Oxides of Nitrogen}

The term NOx is known for particles containing one nitrogen and at least one oxygen molecule. It is by and large intended to fuse nitrous oxide even though nitrous oxide is an inactive oxide of nitrogen that has numerous utilizations as an oxidizer for rockets and motors, a sedative, and a fuel for vaporized splashes and whipped cream. Nitrous oxide assumes once in a while any role in air contamination; it might significantly affect the ozone layer, and is an ozone harming substance.

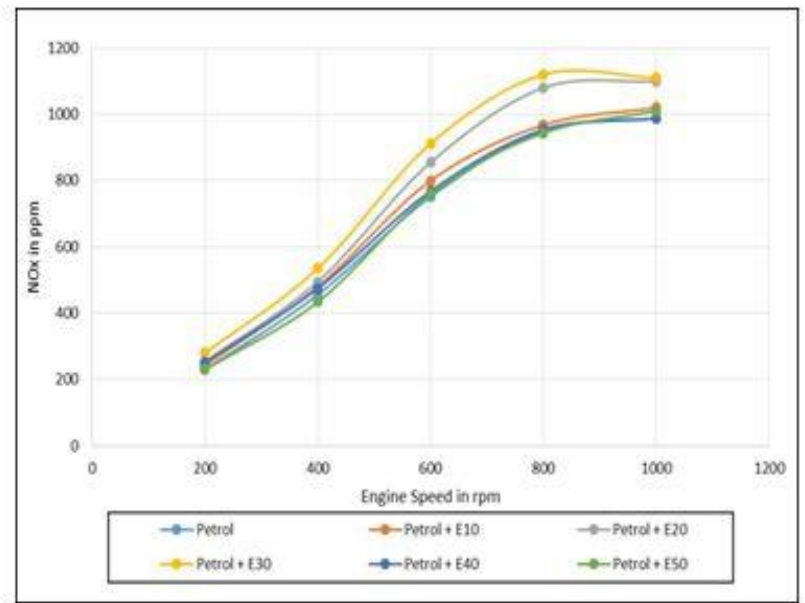

Fig 7: Engine speed in rpm vs NOx in ppm

In figure. 7 shows the NOx emission should be less in order to achieve less air pollution. From the above graph it is observed as the NOx emission is less at $200 \mathrm{rpm}$ with E50 (Ethanol 50\% blended with petrol 50\%) as fuel. The observed NOx emission is nearly $220 \mathrm{ppm}$.

\section{Carbon Monoxide}

Carbon monoxide (CO) is an unscented, dismal, and boring gas that is respectably less thick than air. It is destructive or harmful to people and creatures that utilization haemoglobin as oxygen despite the fact that it is additionally delivered in ordinary creature digestion in low amounts, and is thought to have some typical organic capacities.
Carbon monoxide (CO) emission should be less as per the government rules. The above graph results that the Carbon monoxide emission is less at $400 \mathrm{rpm}$ engine speed and with fuel as E30 (Ethanol 30\% blended with petrol 70\%). The results are $\mathrm{CO}$ emission at the stated condition is observed as 0.04 in \%of volume.

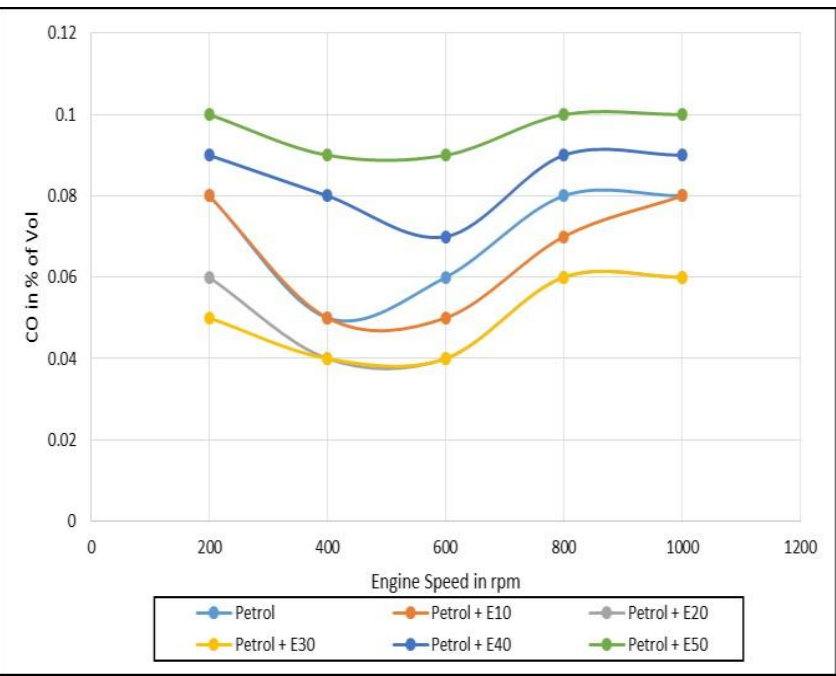

Fig 8: Engine speed in rpm vs CO in \% of volume

\section{Hydrocarbon}

A hydrocarbon is a natural intensify that contains purely of hydrogen and carbon. Hydrocarbons are instances of gathering 14 hydrides. Hydrocarbons from which one hydrogen iota has been expelled are practical gatherings called hydrocarbon.

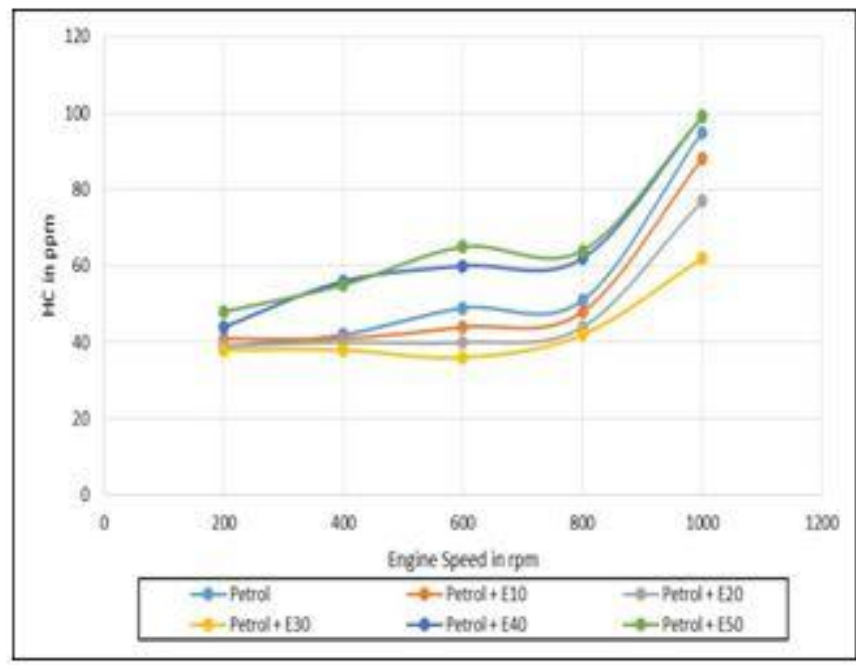

Fig 9: Engine speed in rpm vs Hydrocarbon in ppm

Hydrocarbons are unburnt air fuel mixture that is send into the engine for combustion process. If the hydrocarbon emission is high the engine efficiency decreased and vice versa. From the above graph the results concluded at 600 rpm engine speed with fuel as E30 (Ethanol 30\% blended with petrol $70 \%$ ) is nearly $38 \mathrm{ppm}$

\section{DISCUSSIONS}

From the above graphs the emission of the SI

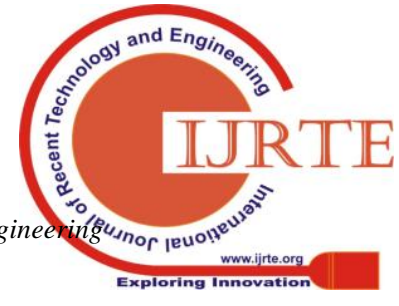


engine is observed and the discussions are as follows:

Fig 4 shows the graph plotted for engine speed in rpm vs specific fuel consumption of the engine in $\mathrm{kJ} / \mathrm{kg}$. From the graph it is observed that the at $800 \mathrm{rpm}$ the specific fuel consumption for fuel E10 is $0.3 \mathrm{~kJ} / \mathrm{kg}$ which is lesser than the other fuel or the same fuel at various engine speed.

Fig 5 shows the graph plotted for engine speed in rpm vs brake thermal efficiency in \%. The graph shows that at 800 rpm engine speed and petrol as fuel the brake thermal efficiency obtained is $26 \%$. The achieved efficiency is higher when compared to other fuel efficiency at various speeds.

Fig 6 shows the graph plotted for engine speed in rpm vs particulate matter emission from the engine in HSU. From the graph is observed that the particulate emission is less at 200 rpm engine speed with fuel as petrol (E10) as $12 \mathrm{HSU}$.

Fig 7 shows the graph plotted for engine speed in rpm vs NOx in ppm. The nitrogen oxide emission is less at $200 \mathrm{rpm}$ engine speed with fuel as E50. The observed value for nitrogen oxide emission is $220 \mathrm{ppm}$.

Fig 8 shows the graph plotted for engine speed in rpm vs carbon monoxide emission in volume. The $\mathrm{CO}$ emission is less at $400 \mathrm{rpm}$ with fuel as E30. The least $\mathrm{CO}$ emission observed is $0.04 \%$ of volume. Comparatively E30 is better in both 200 and $400 \mathrm{rpm}$ engine speeds.

Fig 9 shows the graph plotted for engine speed in rpm vs Hydrocarbon in ppm. Least Hydrocarbon emission as observed from graph is $36 \mathrm{ppm}$ at engine speed of $600 \mathrm{rpm}$ and fuel as E30.

\section{CONCLUSION}

The SI engine was successfully fabricated and the emission tests are conducted with various blend ratios and results were discussed.

At engine speed $800 \mathrm{rpm}$ with fuel as E10 specific fuel consumption is $0.3 \mathrm{~kJ} / \mathrm{kg}$ which is comparatively lesser.

$>$ The maximum brake thermal efficiency attained is $26 \%$ at $1000 \mathrm{rpm}$ engine speed and by using petrol as fuel.

$>$ Particulate matters emission is less with E10 as fuel is 21 HSU.

$>$ Minimum nitrogen oxides emission is achieved by fuel E50 at $200 \mathrm{rpm}$ speed is $220 \mathrm{ppm}$.

$>$ Carbon monoxide emission is comparatively less at both 200 and $400 \mathrm{rpm}$ when E30 is used as fuel. The least CO emission is $0.04 \%$ of volume.

$>$ Hydrocarbon emission as observed from graph is 36 ppm at engine speed of $600 \mathrm{rpm}$ and fuel as E30.

\section{REFERENCES}

1. PrakharChansauria, R. K. Mandloi, "Effects of Ethanol Blends on Performance of Spark Ignition Engine- A Review", Materials Today: Proceedings, 2018, 5 4066-4077.

2. Mahesh K. Saini, NeelimaGarg, Anil K. Singh, Ajay K. Tyagi, Utpal K. Niyogi and Rakesh K. Khandal, "Ethanol Blended Fuel in India: An Overview", Journal of Biofuels, 2010, 1, 209-219.

3. Victor Davis, S. MohhammedShafee, P. Baskar, "Performance analysis of four stroke SI engine with preheated intake air", Sadgurupublications, 2015, 13, 1277-1284.

4. Krishna Perumal. R, Manoj. R, "Reduction of hydrocarbon by preheating Air-Fuel Mixture by flue gas in S.I. Engines", International Journal on Mechanical Engineering and Robotics (IJMER), 2015, 3, 19-21.
5. MohdNazrullkram Bin MohdAtan, "Experimental investigation on ethanol-petrol blends operating with a petrol engine".

\section{AUTHORS PROFILE}

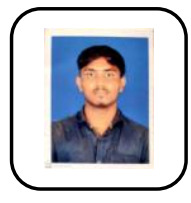

R. Sameeth Raj, UG Student

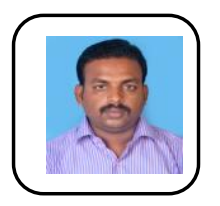

Dr. S Gowthaman, Ph.D., (IC engines), Published 11 papers in international publications, and membership in ISTE,. 